ORIGINAL ARTICLE

\title{
Microsatellite instability and gastric non-invasive neoplasia in a high risk population in Cesena, Italy
}

\author{
M Rugge, G Bersani, R Bertorelle, G Pennelli, V M Russo, F Farinati, D Bartolini, M Cassaro, \\ V Alvisi
}

See end of article for authors' affiliations

....................

Correspondence to: Dr M Rugge, Cattedra di Anatomia Patologica Department of Oncology and Surgical Sciences, Universitò degli Studi di Padova, Via Aristide Gabelli, 61, I-35121 Padova, Italy; massimo.rugge@unipd.it

Accepted for publication 14 February 2005
Background/Aims: In the natural history of gastric cancer, non-invasive neoplasia (NiN) precedes invasive carcinoma. A histological classification of gastric $\mathrm{NiN}$ has recently been proposed by a World Health Organisation international panel of experts. Genetic instability is known to be among the molecular pathways involved in gastric oncogenesis. In this retrospective cross sectional study, microsatellite instability (MSI) was analysed in a consecutive series of $\mathrm{NiN}$ and $\mathrm{NiN}$ related histological alterations from a northern Italian region at high risk for gastric cancer.

Patients/Methods: Fifty five consecutive cases (indefinite for NiN, 29 cases; low grade NiN, 17 cases; high grade $\mathrm{NiN}$, nine cases) were analysed by radioactive polymerase chain reaction and electrophoresis for microsatellite alterations at six loci (BAT25, BAT26, D2S123, D5S346, D17S250, and D3S1317). MSI was defined according to the Bethesda criteria distinguishing: (1) no instability in the analysed loci; (2) low frequency MSI (MSI-L); and (3) high frequency MSI (MSI-H). Immunohistochemical expression of MLH1 and $M S H 2$ proteins was also analysed in all cases.

Results: Overall, MSI was found in 11 of 55 cases (indefinite for $\mathrm{NiN}$, five of 29 (MSI-L, four; MSI-H, one); low grade NiN, three of 17 (MSI-L, one; MSI-H, two); high grade NiN, three of nine (MSI-L, one; MSI-H, two).

Conclusions: In an Italian high risk area for gastric cancer, MSI is part of the spectrum of genetic alterations in gastric non-invasive neoplasia. In European populations at high risk of gastric cancer, DNA repair system alterations are thought to be among the early molecular events in gastric carcinogenesis.
G astric cancer (GC) may coexist with alterations of the adjacent glands, featuring cyto-architectural (de)differentiation somewhere between that of the native mucosa and that of the concomitant carcinoma. ${ }^{12}$ Such phenotypic alterations, considered the precursor of malignant transformation, have been defined as epithelial dysplasia. Whereas in the Western literature the histological category of dysplasia rules out spreading of neoplastic epithelia into the lamina propria, the Eastern literature allows for the coexistence of dysplasia with intramucosal cancer cells. ${ }^{3-5}$ The World Health Organisation (WHO) has recently redefined dysplasia as non-invasive neoplasia (NiN) and longterm follow up studies have shown that, in the natural history of GC, NiN precedes invasive adenocarcinoma. ${ }^{67}$

\section{"Mismatch repair defects lead to high frequency micro- satellite instability"}

Genetic instability resulting from the inactivation of mismatch repair system genes (mostly MLH1, MSH2, and MSH6) is known to be one of the molecular pathways involved in gastric oncogenesis..$^{8-18}$ Mismatch repair defects lead to high frequency microsatellite instability (MSI). Germline defects in mismatch repair have been associated with hereditary non-polyposis colorectal cancer and GC is listed among the hereditary non-polyposis colorectal cancer related extracolonic cancers. ${ }^{19} 20$

In Asian high risk populations, genetic instability is one of the possible pathways of gastric oncogenesis; however, all but one of the published studies include in the same histological category both non-invasive and early invasive neoplastic lesions. ${ }^{821-25}$
In Italy, Cesena is one of the geographical areas at greatest risk of GC, with an incidence (age standardised rates for the years 1993-1997) of 34.0 for women and 47.2 for men (http:// www.registri-tumori.it/incidenza/gruppi.html).

Our study was designed to assess the prevalence of genetic instability in histological lesions coming within the spectrum of gastric NiN. In a consecutive series of retrospectively selected gastric biopsy samples obtained from northern Italian outpatients, genomic instability was tested using molecular methods; the immunohistochemical expression of the products of two mismatch repair genes (MLHl and MSH2) was also tested.

\section{PATIENTS AND METHODS \\ Patients}

Our retrospective cross sectional study comprised 55 consecutive white patients (M/F, 34/21; mean age, 59 years; range, 46-78), born and living in the Italian area of Cesena. All patients underwent upper gastrointestinal endoscopy for dyspepsia between 1997 and 2000, and one or more of the gastric biopsies (which included at least four samples: two from the antrum and two from the corpus) showed morphological lesions belonging to the spectrum of gastric NiN.

On the basis of their own (colon cancer confirmed before or after the gastric biopsy was obtained) and their family's cancer history, four subjects fulfilled the Amsterdam II criteria for hereditary non-polyposis colorectal cancer. ${ }^{19}{ }^{20}$ A

Abbreviations: GC, gastric cancer; MSI, microsatellite instability; MSI$\mathrm{H} / \mathrm{L}$, high/low frequency of microsatellite instability; MSS, microsatellite stable; NiN, non-invasive neoplasia; PCR, polymerase chain reaction; WHO, World Health Organisation 
history of cancer was recorded in at least one first degree relative of six patients. Family history was negative for cancer in 40 patients and unknown in five subjects.

After the histological diagnosis of NiN (or indefinite for NiN), 40 of 55 patients were followed up with upper gastrointestinal endoscopy for at least six months (mean follow up, 18 months; range, six to 18). Among these patients, six invasive GCs were documented histologically: one adenocarcinoma was detected in a patient enrolled with indefinite for NiN lesions, one patient entered with low grade $\mathrm{NiN}$, and the initial biopsy of the four remaining patients had documented high grade NiN. WHO/UICC postsurgical cancer histotyping and staging were available in two of six patients (one enrolled with indefinite for NiN lesions and one with high grade NiN); both cancers had the glandular phenotype and were pTNM stage I. ${ }^{6}$

\section{METHODS}

\section{Pathological study and histological assessment}

Gastric biopsy samples were fixed in 5\% formalin and embedded in paraffin wax. For the histological assessment, serial histological sections ( $5 \mu \mathrm{m}$ thick) were stained with haematoxylin and eosin. Helicobacter pylori infection was assessed histologically (modified Giemsa stain) on the whole set of biopsy samples obtained during endoscopy.

Histological lesions were jointly assessed by two pathologists according to the international Padova classification and WHO criteria, distinguishing: (1) indefinite for NiN, 29 cases; (2) low grade NiN, 17 cases; and (3) high grade NiN, nine cases. ${ }^{67}$ Cases of NiN coexisting with "suspected invasive neoplasia" were excluded.

\section{Immunohistochemistry for MLH1 and MSH2 gene products}

The expression of MLHI and MSH2 protein was analysed by immunohistochemistry. Tissue sections were incubated with a $1 / 30$ dilution of anti-MLHl antibody (PharMingen International, San Diego, California, USA) or a 1/100 dilution

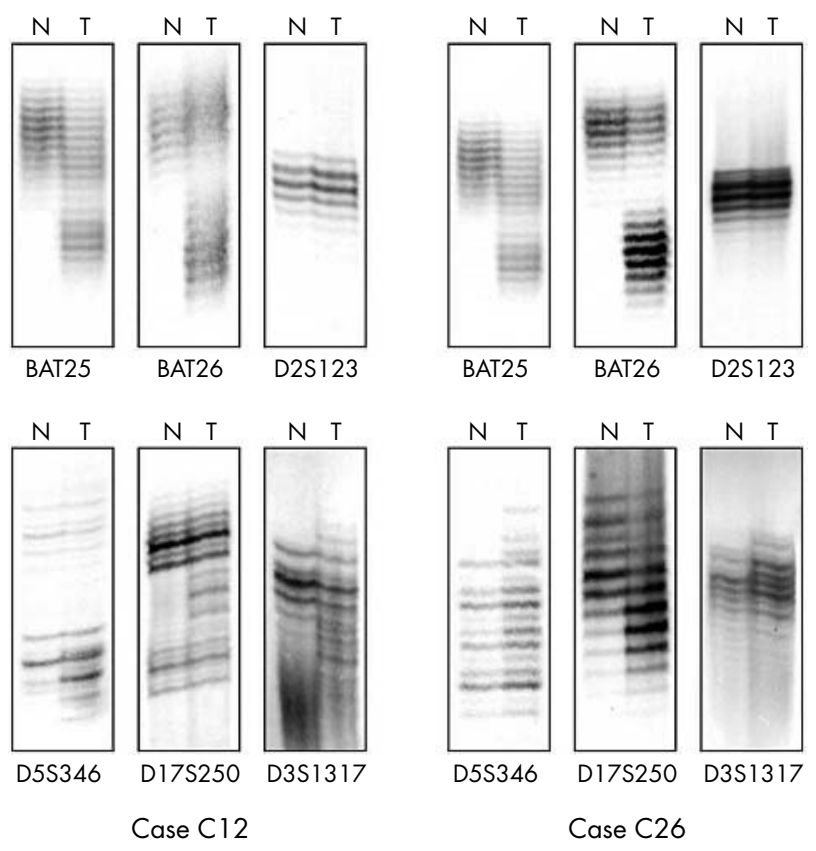

Figure 1 Electrophoretic pattern of two cases showing high frequency microsatellite instability (C12, high grade non-invasive neoplasia; $\mathrm{C} 26$, low grade non-invasive neoplasia). Mobility shifts in five of six of the loci analysed are apparent in the tumours when compared with the normal tissue. $N$, normal biopsy sample; T, tumour biopsy sample. of monoclonal anti-MSH2 (clone AB-2; Oncogene Research Products, San Diego, California, USA). Cases with less than $10 \%$ nuclear reactivity in the target epithelia were considered negative. Normal epithelia were analysed as internal positive controls.

\section{Molecular assessment of microsatellite status}

Six different loci were considered for MSI assessment, including all those recommended by the Bethesda panel for colon cancer (BAT25, BAT26, D5S346, D2S123, and D17S250). ${ }^{19}$ Because allelic loss and/or instability in the region encompassing the VHL gene had previously been described in a series of gastric cancers selected from the same geographical area, an additional marker (D3S1317) was also included at locus $3 \mathrm{p} 26 .^{1326}$

Polymerase chain reaction (PCR) was performed using specific primers in a total volume of $25 \mu \mathrm{l}$ using $200 \mu \mathrm{M}$ dNTPs, 2.0mM $\mathrm{MgCl}_{2}$, I U Amplitaq Gold (Applied Biosystems, Foster City, California, USA), 15 pmol of each primer, $0.7 \mu \mathrm{g} / \mu \mathrm{l}$ bovine serum albumin, and $1 \mu \mathrm{Ci}{ }^{33} \mathrm{P}$-dATP. PCR products were then diluted $1 / 2$ with a $95 \%$ formamide dye solution, heated to $95^{\circ} \mathrm{C}$ for five minutes, and electrophoresed in a denaturing 5\% acrylamide gel containing $8 \%$ urea..$^{28}$ The gel was dried and exposed to $x$ ray film at $-80^{\circ} \mathrm{C}$ for 24-48 hours. MSI was scored according to the presence of a shifted mobility pattern in the DNA PCR products obtained from the target lesions compared with those obtained from normal gastric mucosa (biopsy samples with no NiN or intestinal metaplasia) (fig 1). Samples showing a shifted mobility pattern were double checked. When more than one microsatellite locus was altered (MSI in $\geqslant 30 \%$ of the tested markers), cases were defined as highly unstable (high frequency MSI; MSI-H); cases showing MSI at only one locus (MSI in $<30 \%$ of the tested markers) were categorised as low frequency MSI (MSI-L); cases with no MSI were considered stable (MSS). ${ }^{19}$

\section{Statistical tests}

Frequency tables were analysed using Fisher's exact test and the $\chi^{2}$ test for linear trend was used as appropriate. For all calculations a p value $<0.05$ was considered significant.

\section{RESULTS}

\section{Prevalence of $\boldsymbol{H}$ pylori infection}

Helicobacter pylori was detected histologically in 39 of the 55 cases: 18 of 29 cases indefinite for NiN, 13 of 17 low grade NiN, and eight of nine high grade NiN. No association was detected between MSI phenotype (both MSI-L and MSI-H) and $H$ pylori infection (Fisher's exact test, $\mathrm{p}=0.173$ ).

\section{Microsatellite instability}

We investigated the amplification of six microsatellite loci (BAT25, BAT26, D2S123, D17S250, D5S346, and D3S1317). In 44 of 55 cases, all six loci were successfully amplified. Five and four loci were amplified in five and two cases, respectively. In four cases, only three markers could be amplified.

Overall, the prevalence of the MSI phenotype was 11 of 55 (table 1). In six of 11 cases, only one microsatellite locus was unstable (MSI-L); in the other five cases, two to five loci were unstable (MSI-H) (table 1).

Among indefinite for NiN lesions, the prevalence of MSI was five of 29 (MSI-L, four; MSI-H, one); in low grade NiN, it was three of 17 and two of these were MSI-H. Of the three of nine cases of MSI detected in high grade NiN, two were MSI-H (tables 1, 2). The increasing prevalence of MSI-H in indefinite for NiN lesions, low grade $\mathrm{NiN}$, and high grade NiN was marginally significant $\left(\chi^{2}\right.$ test for linear trend, $\mathrm{p}=0.08)$. 
Table 1 Pathology, MSI, and MSH2/MLH1 protein expression (by immunohistochemistry) in the 11 MSI cases

\begin{tabular}{|c|c|c|c|c|c|c|c|c|c|c|}
\hline \multirow[b]{2}{*}{ Case } & \multirow[b]{2}{*}{ Pathology } & \multicolumn{6}{|c|}{ Microsatellite markers } & \multirow[b]{2}{*}{ MSI } & \multicolumn{2}{|c|}{ Immunohistochemistry } \\
\hline & & BAT25 & BAT26 & D5S346 & D2S123 & D17S250 & D3S1317 & & MSH2 & MLHI \\
\hline C5 & Indefinite for $\mathrm{NiN}$ & - & - & MSI & - & MSI & MSI & MSI-H & Positive & Negative \\
\hline $\mathrm{C} 14$ & Indefinite for $\mathrm{NiN}$ & - & - & - & - & - & MSI & MSI-L & Positive & Positive \\
\hline C190 & Indefinite for $\mathrm{NiN}$ & - & - & - & MSI & - & - & MSI-L & Positive & Positive \\
\hline $\mathrm{C} 20$ & Indefinite for $\mathrm{NiN}$ & - & - & MSI & NA & - & NA & MSI-L & Positive & Positive \\
\hline C31 & Indefinite for $\mathrm{NiN}$ & - & - & - & - & MSI & - & MSI-L & Positive & Positive \\
\hline $\mathrm{C} 18$ & Low grade $\mathrm{NiN}$ & - & - & NA & MSI & - & NA & MSI-L & Negative & Positive \\
\hline $\mathrm{C} 7$ & Low grade NiN & - & NA & NA & MSI & MSI & NA & MSI-H & Positive & Negative \\
\hline $\mathrm{C} 26$ & Low grade NiN & MSI & MSI & MSI & - & MSI & MSI & MSI-H & Negative & Positive \\
\hline C9 & High grade $\mathrm{NiN}$ & - & - & NA & NA & MSI & NA & MSI-L & Positive & Positive \\
\hline $\mathrm{C}^{*}$ & High grade $\mathrm{NiN}$ & - & - & MSI & MSI & - & - & MSI-H & Negative & Positive \\
\hline $\mathrm{Cl} 2^{*}$ & High grade $\mathrm{NiN}$ & MSI & MSI & MSI & - & MSI & MSI & $\mathrm{MSI}-\mathrm{H}$ & Positive & Negative \\
\hline
\end{tabular}

${ }^{*} \mathrm{MSI}$ cases in which invasive adenocarcinoma was histologically diagnosed during short term follow up.

MSI, microsatellite instability; MSI-H/L, high/low frequency of microsatellite instability; MSS, microsatellite stable; NA, not assessable; NiN, non-invasive neoplasia.

\section{Immunohistochemistry for MLH1 and MSH2 gene products}

None of the 55 cases lacked both MLH1 and MSH2 signals. Overall, no MLHI and MSH2 immunostaining was found in nine cases (table 2): six of the nine were associated with MSI (one of five cases indefinite for NiN; three of three cases of low grade NiN; and two of three cases of high grade NiN; tables 1, 2). No immunostaining for MLH1 or MSH2 was found in three of the 44 MSS cases (one indefinite for NiN; two high grade NiN; table 2). A significant association was found between microsatellite status (MSI $v$ MSS) and immunophenotype (negative $v$ positive immunostaining for MLH1 or MSH2) (Fisher's exact test, $p=0.00001$ ).

All five MSI-H cases were associated with loss of MLHI or MSH2 expression (table 1), whereas only one of the six MSI-L cases showed no immunoreactivity for one of the target proteins (MSH2) (Fisher's exact test, $\mathrm{p}=0.01298$ ).

\section{GCs detected during short term follow up and microsatellite status at initial biopsy}

Six GCs were detected in the 44 patients who underwent endoscopic follow up. Two of these six patients were enrolled with high grade NiN, associated with MSI-H (table 1). The other four patients had the MSS phenotype.

\section{DISCUSSION}

A relation between gastric NiN and adenocarcinoma has been demonstrated by clinicopathological follow up studies. ${ }^{29}$ In gastric oncogenesis, both environmental and host related gene silencing/activation have been considered. ${ }^{30-32}$

In our present series of gastric precancerous lesions, the prevalence of $H$ pylori infection was higher than $80 \%$, and no association was found between infection and MSI phenotype. $^{29} 33$

MSI has been considered among the molecular pathways leading to the development of hereditary (gastrointestinal) cancers, and clinical criteria (Amsterdam II) have been proposed to identify patients at high risk of such cancer syndromes. ${ }^{10} 19203435$ Available information on MSI in both precancerous and advanced gastric neoplasia is inconsistent (tables 3,4). In our present study, four patients fulfilled the Amsterdam II criteria, but none revealed an MSI positive phenotype. $^{35}$

In comparing the results of our study with existing data, two main factors must be taken into account, namely: (1) most of the available information is based on the genotyping of Asian patients with cancer and the ethnic setting is considered a major source of heterogeneity; (2) in all but one study, precancerous lesions have been histologically classified according to Japanese criteria, which include both noninvasive and early invasive neoplastic lesions in the same histological category. ${ }^{42}{ }^{42-44}$ Moreover, variability in: (a) the molecular assessment of MSI status (radioactive $v$ nonradioactive methods), (b) the number/location of considered loci, (c) the definition of mutator phenotype, and (d) the clinical setting from which samples are obtained (coexistence/absence of precancerous lesions with invasive neoplasia) all make it difficult to compare available data with each other, and with the results of our present study. ${ }^{22-24} 36$ 45-49 Consequently, it seems reasonable, once again, to subscribe to the recommendation of a standardised approach to both the method(s) of assessing MSI and the strict use of internationally validated histological classifications. ${ }^{50} 51$

In advanced GC, the prevalence of MSI ranges between 5\% and $46 \%$, with significant differences between different ethnic groups. ${ }^{15} 52$ It is noteworthy, however, that some Eastern series significantly associate the MSI phenotype with the foveolar type of GC, which theoretically occurs via a carcinogenic pathway different from that of gastric mucosa intestinalisation. ${ }^{21}$ In our present series, all cases showed extensive intestinal metaplasia ( $\mathrm{NiN}$ arising in intestinalised glands).

The relations between intestinal metaplasia (both with and without GC) and microsatellite status have been investigated

Table $2 \mathrm{MSI}$ and loss of $\mathrm{MSH} 2 / \mathrm{MLH1}$ expression in lesions indefinite for gastric $\mathrm{NiN}$, low grade $\mathrm{NiN}$, and high grade $\mathrm{NiN}$

\begin{tabular}{lllll}
\hline MSI and MSH2/MLH1 expression (IHC) & $\begin{array}{l}\text { Indefinite for NiN } \\
\mathbf{2 9} \text { cases (\%) }\end{array}$ & $\begin{array}{l}\text { Low grade NiN } \\
17 \text { cases }(\%)\end{array}$ & $\begin{array}{l}\text { High grade NiN } \\
9 \text { cases (\%) }\end{array}$ & Total 55 cases \\
\hline MSI (MSI-L and MSI-H) & $5(17.2)$ & $3(17.6)$ & $3(33.3)$ & 11 \\
MSI-L & $4(13.8)$ & $1(5.9)$ & $1(11.1)$ & 6 \\
MSI-H & $1(3.4)$ & $2(11.8)$ & $2(22.2)$ & 5 \\
Loss of MSH2 protein (IHC) & $1(3.4)($ MSS) & $2(11.8)(1 \mathrm{MSI}-\mathrm{H} ; 1$ MSI-L) & $1(11.1)(\mathrm{MSI}-\mathrm{H})$ & 4 \\
Loss of MLH1 protein (IHC) & $1(3.4)(\mathrm{MSI}-\mathrm{H})$ & $1(5.9)(\mathrm{MSI}-\mathrm{H})$ & $3(33.3)(1 \mathrm{MSI}-\mathrm{H} ; 2 \mathrm{MSS})$ & 5 \\
\hline
\end{tabular}

IHC, immunohistochemistry; MSI, microsatellite instability; MSI-H/L, high/low frequency microsatellite instability; MSS, microsatellite stability; NiN, non-invasive neoplasia. 
Table 3 MSI in gastric IM

\begin{tabular}{|c|c|c|c|c|c|}
\hline \multirow[b]{2}{*}{ First author } & \multicolumn{2}{|l|}{ IM } & \multicolumn{2}{|l|}{ MSI } & \multirow[b]{2}{*}{ Microsatellite markers } \\
\hline & $\begin{array}{l}\text { Without } \\
\text { coexisting GC }\end{array}$ & $\begin{array}{l}\text { With } \\
\text { coexisting GC }\end{array}$ & $\begin{array}{l}\text { MSI-L } \\
(\%)\end{array}$ & $\begin{array}{l}\text { MSI-H } \\
(\%)\end{array}$ & \\
\hline Garay $(2004)^{36}$ & 58 & & 0 & & BAT26, D3S1067, D3S1262, D5S346, D12S347, D12S351 \\
\hline Roa $(2003)^{37}$ & 22 & & $13(59)$ & 0 & $\begin{array}{l}\text { BAT25, BAT26, BAT40, D2S123, D3S1067, D3S1262, D3S3640, D5S346, } \\
\text { P53CA, D17S250, C17S588, D18S55 }\end{array}$ \\
\hline $\operatorname{Kim}(2002)^{38}$ & & 15 & 0 & & BAT25, BAT26, D2S123, D5S346, D17S250, D13S170,TP53 \\
\hline $\operatorname{Jin}(2001)^{25}$ & & 17 & 0 & & BAT25, BAT26, D2S123, D5S346, D17S250 \\
\hline Leung $(2000)^{39}$ & 45 & 30 & $\begin{array}{l}17(37.8) \\
12(40)\end{array}$ & $\begin{array}{l}3(6.7) \\
4(13.3)\end{array}$ & BAT25, BAT26, BAT40, D2S123, D5S346, D13S170, D17S250, TP53 \\
\hline Kobayashi $(2000)^{40}$ & & 33 & $11(33)$ & 0 & $\begin{array}{l}\text { BAT25, BAT40, D2S123, D1S103, D3S1067, D5S107, D13153, D17S261, } \\
\text { D18S34 }\end{array}$ \\
\hline Hamamoto $(1997)^{41}$ & & 15 & $4(26.7)$ & & BATRII, BAT25, BAT26, BAT40, D1S191, D7S486, D11S29, TP53, D17S855 \\
\hline Semba $(1996)^{8}$ & & 9 & $3(33)$ & & $\begin{array}{l}\text { D2S123, D2S110, D2S136, D3S1O67, D5S5O5, D7S486, D11S29, TP53, } \\
\text { D17S855 }\end{array}$ \\
\hline
\end{tabular}

MSI-L and MSI-H are distinguished according to the criteria adopted by each author.

GC, gastric cancer; IM, intestinal metaplasia; MSI, microsatellite instability; MSI-H/L, high/low frequency microsatellite instability.

extensively, with divergent results (table 3). Because only NiNs arising in intestinalised glands were studied here, it is worth briefly summarising the results of other studies in which MSI was tested in intestinal metaplasia (table 3). When MSI-H was distinguished from MSI-L, the prevalence of MSI-H ranged from $0 \%$ to $13 \%$ (table 3 ). The fact that when intestinal metaplasia coexists with GC, the same MSI pattern is detectable in both lesions, biologically supports the precancerous significance of metaplastic transformation. Such an observation is consistent with the hypothesis that the "field cancerisation process" in the stomach is mucosal intestinalisation. ${ }^{53}$

"The prevalence of a high frequency of microsatellite instability increased from indefinite for non-invasive neoplasia (NiN) lesions, to low grade $\mathrm{NiN}$, to high grade $\mathrm{NiN}$, is consistent with the hypothesis that the prevalence of genotype alterations increases with the dedifferentiation of the histological phenotype ${ }^{\prime \prime}$

Data pertaining to MSI in advanced precancerous lesions must be considered with caution. Western and Eastern publications give different names to the same histological lesion, or include different histological alterations under the same histological label; as a result, the available data on the genotyping of advanced gastric precancerous lesions are bewildering.

When the spectrum of gastric precancerous alterations is considered as a whole (adenoma or dysplasia or non-invasive neoplasia of both low and high grade), the prevalence of MSI ranges from $0 \%$ to $42 \%$ (table 4 ), and it could be said that the prevalence of the mutator phenotype is higher the larger the number of microsatellites tested. When MSI-H is defined according to the criteria recommended for colorectal cancer, the prevalence of MSI in low grade lesions is consistently reported to be lower than 10\%. Applying the current internationally validated classification of gastric precancerous lesions to a series of Japanese patients, Jin et al found MSI-H in 5\% and 19\% of low grade and high grade NiNs, respectively. Similarly, our present study detected a prevalence of MSI-H that increased from indefinite for NiN lesions $(3.4 \%)$ to low grade $\mathrm{NiN}(11.8 \%)$, to high grade NiN $(22.2 \%)$, which is consistent with the hypothesis that the prevalence of genotype alterations increases with the dedifferentiation of the histological phenotype. In line with the histological classification adopted, our results provide the first evidence of MSI being involved in non-invasive

Table $4 \mathrm{MSI}$ in gastric advanced precancerous lesions

\begin{tabular}{|c|c|c|c|c|c|}
\hline \multirow[b]{2}{*}{ First author } & \multicolumn{2}{|c|}{ Adenoma/Dysplasia/NiN } & \multicolumn{2}{|l|}{ MSI } & \multirow[b]{2}{*}{ Microsatellite markers } \\
\hline & $\begin{array}{l}\text { Without } \\
\text { coexisting GC }\end{array}$ & $\begin{array}{l}\text { With coexisting } \\
\text { GC }\end{array}$ & $\begin{array}{l}\text { MSI-L } \\
(\%)\end{array}$ & $\begin{array}{l}\text { MSI-H } \\
(\%)\end{array}$ & \\
\hline Abraham $(2003)^{21}$ & $\begin{array}{l}12 \text { LG-GED } \\
4 \text { HG-GED }\end{array}$ & 2 HG-GED & $\begin{array}{ll}0 \\
0\end{array}$ & $\begin{array}{l}1(8) \\
2(33)\end{array}$ & BAT25, BAT26, D2S123, D5S346,D17S250 \\
\hline $\operatorname{Jin}(2001)^{25}$ & $\begin{array}{l}20 \text { LG-NiN } \\
32 \text { HG-NiN }\end{array}$ & & $\begin{array}{l}0 \% \\
4(12.5)\end{array}$ & $\begin{array}{l}1(5) \\
6(18.7)\end{array}$ & $\begin{array}{l}\text { BAT26, D2S115, D4S404, D5S178, IL9, D6S265, D7S490, D11S900, } \\
\text { MYH6, TP53, D17S1176, D18S46, D21S1407 }\end{array}$ \\
\hline Lee $(2002)^{22}$ & $75 \mathrm{Ad}$ & $35 \mathrm{Ad}$ & $\begin{array}{l}7(9) \\
3(9)\end{array}$ & $\begin{array}{l}2(3) \\
6(17)\end{array}$ & BAT26, D2S123, D5S346, D17S250, BAT25 \\
\hline Chang $(2002)^{23}$ & $67 \mathrm{Ad}$ & $65 \mathrm{Ad}$ & $\begin{array}{l}7(10.4) \\
8(12.3)\end{array}$ & & BAT26 \\
\hline $\begin{array}{l}\text { Endoh }(2000)^{14} \\
\text { Ohmura }(2000)^{42}\end{array}$ & $\begin{array}{l}24 \\
13 \text { LG } \\
20 \mathrm{HG}\end{array}$ & & $\begin{array}{l}8(33) \\
? \\
?\end{array}$ & $\begin{array}{l}1(7.7) \\
8(40)\end{array}$ & $\begin{array}{l}\text { BAT26 } \\
\text { D2S1 15, D4S404, D5S178, IL9, D6S265, D7S490, D1 1S900, MYH6, } \\
\text { TP53, D17S1 176, D18S46, D21S1407 }\end{array}$ \\
\hline $\operatorname{Kim}(2000)^{16}$ & & $\begin{array}{l}41 \text { LG-Ad } \\
22 \text { HG-Ad }\end{array}$ & $\begin{array}{l}9(22) \\
4(18)\end{array}$ & & 50 loci \\
\hline Isogaki $(1999)^{24}$ & 13 & 37 & $\begin{array}{l}1(7.6) \\
6(16.2)\end{array}$ & & D1S116, D2S136, D6S87, D10S197, TP53 \\
\hline Semba $(1996)^{8}$ & & 12 & $5(42)$ & & $\begin{array}{l}\text { D2S123, D2S110, D2S136, D3S1O67, D5S5O5, D7S486, D1 1S29, } \\
\text { TP53, D17S855 }\end{array}$ \\
\hline
\end{tabular}




\section{Take home messages}

- We have provided the first evidence that microsatellite instability does occur in gastric non-invasive neoplasia (NiN) in white populations from high risk areas

- In European populations at high risk of gastric cancer, DNA repair system alterations are early molecular events in gastric carcinogenesis

- Our results support the hypothesis that low and high grade gastric NiN are different phenotypes of the same biological disease

neoplastic alterations originating from gastric intestinalised glands in a white population at high risk for GC.

Loss of immunohistochemical expression of DNA repair system gene products has been considered a marker of genetic instability, and loss of one of the target proteins has been demonstrated in more than $85 \%$ of MSI cases. ${ }^{54}$ In our present series of biopsy tissue samples, the significant correlation found between MSI phenotype (all MSI cases and the MSI-H subgroup) and MLHI/MSH2 protein loss suggests that immunohistochemistry should be considered as a suitable method for MSI assessment in gastric precancerous lesions.

In conclusion, the results of our study provide the first evidence that MSI does occur in gastric NiN in white populations, also supporting the hypothesis that the two grades (low and high) of gastric NiN may represent different phenotypes of the same biological disease.

\section{ACKNOWLEDGEMENTS}

We thank Dr G Caruso, head of the "Suzzi" Laboratory of Diagnostic Pathology, Cesena, Italy, who kindly provided some of the cases for this study, and who was also personally involved in the histological assessment of the whole series of collected specimens. G Leandro (MD and biostatistician) performed the statistical analysis. This study was supported by the MIUR, the AIRC, the "Roberto Farini" Foundation for Gastrointestinal Research, and the "CCC-Cittadella Contro il Cancro" Association.

\section{Authors' affiliations}

M Rugge, R Bertorelle, G Pennelli, M Cassaro, Department of Oncology and Surgical Sciences, University of Padova, I-35121 Padova, Italy G Bersani, Gastroenterology Unit, Malatesta-Novello Hospital, I-47023 Cesena, Italy

V M Russo, Department of Pathology, San Luigi Hospital, I-95100

Catania, Italy

F Farinati, Department of Gastroenterology and Surgical Sciences, University of Padova, I-35128 Padova, Italy

D Bartolini, Department of Pathology, Maurizio Bufalino Hospital, I-47023 Cesena, Italy

V Alvisi, School of Gastroenterology, University of Ferrara, l-47023 Cesena, Italy

\section{REFERENCES}

1 Jass JR. A classification of gastric dysplasia. Histopathology 1983;7:181-93

2 Lewin KJ. Nomenclature problems of gastrointestinal epithelial neoplasia. Am J Surg Pathol 1988;22:1043-7.

3 Morson BC, Sobin LH, Grundmann E, et al. Precancerous conditions and epithelial dysplasia in the stomach. J Clin Pathol 1980;33:711-21.

4 Riddell RH, Iwafuchi M. Problems arising from eastern and western classification systems for gastrointestinal dysplasia and carcinoma: are they resolvable? Histopathology 1988;33:197-202.

5 Schlemper RJ, Riddell RH, Kato Y, et al. The Vienna classification of gastrointestinal epithelial neoplasia. Gut 2000;47:251-5.

6 Fenoglio-Preiser C, Carneiro F, Correa P, et al. Pathology and genetics. In: Hamilton SR, Aaltonen LA, eds. Tumors of the digestive system. Lyon: IARC Press, 2000:39-52.

7 Rugge M, Correa P, Dixon MF, et al. Gastric dysplasia: the Padova international classification. Am J Surg Pathol 2000;24:167-76.
8 Semba S, Yokozaki H, Yamamoto S, et al. Microsatellite instability in precancerous lesions and adenocarcinomas of the stomach. Cancer 1996;77:1620-7.

9 Ottini L, Palli D, Falchetti $M$, et al. Microsatellite instability in gastric cancer is associated with tumor location and family history in a high-risk population from Tuscany. Cancer Res 1997;57:4523-9.

10 Luinetti O, Fiocca R, Villani L, et al. Genetic pattern, histological structure, and cellular phenotype in early and advanced gastric cancers: evidence for structure-related genetic subsets and for loss of glandular structure during progression of some tumors. Hum Pathol 1998;29:702-9.

11 Rugge M, Shiao YH, Guido M, et al. Microsatellite instability and gastric cancer subtypes. Hum Pathol 1999;30:108-9.

12 Sepulveda AR, Santos AC, Yamaoka Y, et al. Marked differences in the frequency of microsatellite instability in gastric cancer from different countries. Am J Gastroenterol 1999;94:3034-8.

13 Shiao YH, Bovo D, Guido M, et al. Microsatellite instability and/or loss of heterozygosity in young gastric cancer patients in Italy. Int J Cancer 1999;82:59-62.

14 Endoh Y, Sakata K, Tamura G, et al. Cellular phenotypes of differentiatedtype adenocarcinomas and precancerous lesions of the stomach are dependent on the genetic pathways. J Pathol 2000;191:257-63.

15 Hayden JD, Cawkwell L, Dixon MF, et al. A comparison of microsatellite instability in early onset gastric carcinomas from relatively low and high incidence European populations. Int J Cancer 2000;85:189-91.

16 Kim HS, Woo DK, Bae SI, et al. Microsatellite instability in the adenomacarcinoma sequence of the stomach. Lab Invest 2000;80:57-64.

17 Fang DC, Wang RQ, Yang SM, et al. Mutation and methylation of hmlhl in gastric carcinomas with microsatellite instability. World J Gastroenterol 2003;9:655-9.

18 Lawes DA, Sengupta S, Boulos PB. The clinical importance and prognostic implications of microsatellite instability in sporadic cancer. Eur J Surg Oncol 2003;29:201-12.

19 Boland CR, Thibodeau SN, Hamilton SR, et al. A National Cancer Institute workshop on microsatellite instability for cancer detection and familial predisposition: development of international criteria for the determination of microsatellite instability in colorectal cancer. Cancer Res 1998;58:5248-57.

20 Boland CR. Molecular genetics of hereditary nonpolyposis colorectal cancer. Ann N Y Acad Sci 2000;910:50-9.

21 Abraham SC, Park SJ, Lee JH, et al. Genetic alterations in gastric adenomas of intestinal and foveolar phenotypes. Mod Pathol 2003;16:786-95.

22 Lee JH, Abraham SC, Kim HS, et al. Inverse relationship between APC gene mutation in gastric adenomas and development of adenocarcinoma. Am J Pathol 2002;161:611-18.

23 Chang MS, Kim HS, Kim CW, et al. Epstein-Barr virus, p53 protein, and microsatellite instability in the adenoma-carcinoma sequence of the stomach. Hum Pathol 2002;33:415-20.

24 Isogaki J, Shinmura K, Yin W, et al. Microsatellite instability and K-ras mutations in gastric adenomas, with reference to associated gastric cancers Cancer Detect Prev 1999;23:204-14.

25 Jin Z, Tamura G, Satoh M, et al. Absence of BAT-26 instability in gastric intestinal metaplasia. Pathol Int 2001;51:473-5.

26 Gallinger S, Aronson M, Shayan K, et al. Gastrointestinal cancers and neurofibromatosis type 1 features in children with a germline homozygous MLH1 mutation. Gastroenterology 2004; 126:576-85.

27 Dietmaier W, Wallinger S, Bocker T, et al. Diagnostic microsatellite instability: definition and correlation with mismatch repair protein expression. Cancer Res 1997;57:4749-56.

28 Li H, Schmidt L, Duh F, et al. Three polymorphic dinucleotide repeats near the von Hippel Lindau (VHL) disease gene on human chromosome 3: D3S587; D3S1317; D3S1435. Hum Mol Genet 1993;2:1326.

29 Rugge M, Cassaro M, CDi Mario F, et al. The long term outcome of gastric non-invasive neoplasia. Gut 2003;52:1111-16.

30 Tahara, E. Genetic pathways of two types of gastric cancer. IARC Sci Publ 2004; 157:327-49.

31 Uemura N, Okamoto S, Yamamoto S, et al. Helicobacter pylori infection and the development of gastric cancer. N Engl J Med 2001;345:784-9.

32 Woerner SM, Benner A, Sutter C, et al. Pathogenesis of DNA repair-deficient cancers: a statistical meta-analysis of putative real common target genes. Oncogene 2003;22:2226-35.

33 Kashiwagi K, Watanabe M, Ezaki T, et al. Clinical usefulness of microsatellite instability for the prediction of gastric adenoma or adenocarcinoma in patients with chronic gastritis. Br J Cancer 2000;82:1814-18.

34 Buonsanti G, Calistri D, Padovan L, et al. Microsatellite instability in intestinaland diffuse-type gastric carcinoma. J Pathol 1997;182:167-73.

35 Keller G, Rudelius $M$, Vogelsang $H$, et al. Microsatellite instability and loss of heterozygosity in gastric carcinoma in comparison to family history. Am J Pathol 1998;152:1281-9.

36 Garay J, Bravo JC, Correa P, et al. Infrequency of microsatellite instability in complete and incomplete gastric intestinal metaplasia. Hum Pathol 2004;35: 102-6.

37 Roa JC, Villaseca MA, Roa I, et al. Microsatellite instability and loss of heterozygosity in chronic gastritis. Rev Med Chil 2003;131:1365-74.

$38 \mathrm{Kim}$ SS, Bhang CS, Min KO, et al. p53 mutations and microsatellite instabilities in the subtype of intestinal metaplasia of the stomach. J Korean Med Sci 2002;17:490-6.

39 Leung WK, Kim JJ, Kim JG, et al. Microsatellite instability in gastric intestinal metaplasia in patients with and without gastric cancer. Am J Pathol 2000;156:537-43

40 Kobayashi K, Okamoto T, Takayama S, et al. Genetic instability in intestinal metaplasia is a frequent event leading to well-differentiated early 
41 Hamamoto $\mathrm{T}$, Yokozaki $\mathrm{H}$, Semba $\mathrm{S}$, et al. Altered microsatellites in incomplete-type intestinal metaplasia adjacent to primary gastric cancers. J Clin Pathol 1997;50:841-6.

42 Ohmura K, Tamura G, Endoh Y, et al. Microsatellite alterations in differentiated-type adenocarcinomas and precancerous lesions of the stomach with special reference to cellular phenotype. Hum Pathol 2000;31:1031-5

43 Sepulveda AR, Wu L, Ota H, et al. Molecular identification of main cellular lineages as a tool for the classification of gastric cancer. Hum Pathol 2000;31:566-74.

44 Theuer CP, Campbell BS, Peel DJ, et al. Microsatellite instability in Japanese vs. European American patients with gastric cancer. Arch Surg 2002;137:960-5.

45 Buonsanti G, Presciuttini S, Radice P, et al. Rapid assessment of replication error phenotype in gastric cancer. Diagn Mol Pathol 1998;7:168-73.

46 Bovo D, Rugge M, Shiao YH. Origin of spurious multiple bands in the amplification of microsatellite sequences. Mol Pathol 1999;52:50-1.

47 Halling KC, Harper J, Moskaluk CA, et al. Origin of microsatellite instability in gastric cancer. Am J Pathol 1999;55:205-11.
48 Santos AC, Yamaoka Y, Graham DY, et al. Variability in the interpretation of microsatellite patterns with different electrophoretic conditions. Mol Pathol 1999:52:302-4.

49 Musulen E, Moreno V, Reyes G, et al. Standardized approach for microsatellite instability detection in gastric carcinomas. Hum Pathol 2004;35:335-42.

50 Genta RM, Rugge M. Gastric precancerous lesions: heading for an international consensus. Gut 1999;45(suppl 1):15-18.

51 Gonzalez-Garcia I, Moreno V, Navarro M, et al. Standardized approach for microsatellite instability detection in colorectal carcinomas. J Natl Cancer Inst 2000;92:544-9.

52 Hayden JD, Martin IG, Cawkwell L, et al. The role of microsatellite instability in gastric carcinoma. Gut 1998;42:300-3.

53 Garcia SB, Park HS, Novelli M, et al. Field cancerization, clonality, and epithelial stem cells: the spread of mutated clones in epithelial sheets. J Pathol 1999; 187:61-81.

54 Baek MJ, Kang H, Kim SE, et al. Expression of hmlhl is inactivated in the gastric adenomas with enhanced microsatellite instability. $\mathrm{Br} J$ Cancer 2001;85:1147-52.

\section{Call for papers}

11 th European Forum on Quality Improvement in Health Care 26-28 April 2006, Prague, Czech Republic

Deadline 30 September 2005.

For further information and to submit online go to: www.quality.bmipg.com 